\title{
Central nervous system recurrence of desmoplastic small round cell tumor following aggressive multimodal therapy: A case report
}

\author{
KATSUTSUGU UMEDA ${ }^{1}$, SATOSHI SAIDA ${ }^{1}$, HIDEKI YAMAGUCHI ${ }^{1}$, SHINYA OKAMOTO ${ }^{2}$, \\ TAKESHI OKAMOTO ${ }^{3}$, ITARU KATO ${ }^{1}$, HIDEFUMI HIRAMATSU ${ }^{1}$, TSUYOSHI IMAI ${ }^{4}$, \\ TAKESHI KODAIRA $^{5}$, TOSHIO HEIKE ${ }^{1}$, SOUICHI ADACHI ${ }^{6}$ and KEN-ICHIRO WATANABE ${ }^{1}$
}

\author{
Departments of ${ }^{1}$ Pediatrics and ${ }^{2}$ Surgery and ${ }^{3}$ Orthopedic Surgery, Graduate School of Medicine, Kyoto University, \\ Kyoto 606-8507; ${ }^{4}$ Department of Pediatrics, Otsu Red Cross Hospital, Otsu, Shiga 520-8511; \\ ${ }^{5}$ Department of Radiation Oncology, Aichi Cancer Center Hospital, Nagoya, Aichi 464-8681; \\ ${ }^{6}$ Human Health Science, Graduate School of Medicine, Kyoto University, Kyoto 606-8507, Japan
}

Received October 23, 2014; Accepted August 5, 2015

DOI: $10.3892 / \mathrm{ol} .2015 .3928$

\begin{abstract}
Patients with desmoplastic small round cell tumors (DSRCTs) have an extremely poor outcome despite the use of aggressive therapy. The current study presents the case of 16-year-old male with metastatic DSRCT, in which multimodal therapy, including intensive chemotherapies using frequent autologous stem cell support, gross resection of primary and metastatic lesions, and whole abdominopelvic intensity-modulated radiation therapy, was administered. Subsequent to these treatments, there was no evidence of active disease. However, cerebellar and pineal body lesions, and bone metastasis to the left humerus were detected 1 year and 2 months after the initial diagnosis. Combination chemotherapy with irinotecan and temozolomide was initially effective against the central nervous system (CNS) metastatic lesions; however, the patient succumbed due to progressive CNS disease after seven courses of combination chemotherapy. Additional studies are required to accumulate information regarding CNS recurrence of DSRCT.
\end{abstract}

\section{Introduction}

Desmoplastic small round cell tumors (DSRCTs) are rare and aggressive neoplasms that predominantly occur in young adults, with $\sim 90 \%$ of cases occurring in males (1). To date, $<200$ cases of DSRCTs have been reported in the literature. Patients typically present with a large intra-abdominal or pelvic mass with peritoneal and omental spread of the tumor, lymph node involvement, and multiple metastases to the liver,

Correspondence to: $\mathrm{Dr}$ Katsutsugu Umeda, Department of Pediatrics, Graduate School of Medicine, Kyoto University, 54 Kawahara-cho, Shogoin, Sakyo-ku, Kyoto 606-8507, Japan E-mail: umeume@kuhp.kyoto-u.ac.jp

Key words: desmoplastic small round cell tumor, central nervous system, multimodal therapy, autologous stem cell transplantation lungs and bone; however, spread to the bone marrow or the central nervous system (CNS) is rare (2). Typical symptoms include abdominal distension, abdominal pain and emesis. Characteristic histological findings include nests of small round cells, which are positive for epithelial (cytokeratins and epithelial membrane antigen), mesenchymal (vimentin), neural [neuron-specific enolase and cluster of differentiation (CD)56] and myogenic (desmin) markers, and embedded in desmoplastic stroma. The definitive diagnosis of DSRCT is based on the detection of the Ewing' sarcoma (EWS)/Wilm's tumor protein 1 (WT1) fusion gene (3).

The P6 protocol, a high-dose alkylator-based regimen, is the most common treatment for DSRCT; $90 \%$ of treated patients exhibit a partial or complete response (3). However, despite the combination of multi-agent chemotherapies, surgery and local irradiation treatments available, the outcome of DSRCT remains extremely poor, with a 5-year overall survival rate of $\sim 15 \%$, due to markedly high rates of disease progression and relapse $(3,4)$. Generally, relapses present as a local recurrence and/or hematogenous or lymphogenous metastasis $(1,3,4)$. Until now, CNS recurrence had not been reported. The present study reports the case of a 16-year-old male with metastatic DSRCT who developed recurrence in the CNS following aggressive multimodal treatment, including intensive chemotherapy using frequent autologous stem cell support. Written informed consent was obtained from the patient's family and the study was approved by the ethics committee of the Graduate School of Medicine, Kyoto University (Kyoto, Japan).

\section{Case report}

In May 2012, a 16-year-old male patient was admitted to Otsu Red Cross Hospital (Otsu, Japan) with a 2 month history of progressive abdominal pain, weight loss, dyschezia and hematochezia. The patient's medical history was unremarkable. Abdominal magnetic resonance imaging (MRI) and ${ }^{18} \mathrm{~F}$-fluorodeoxyglucose positron emission tomography-computed tomography (CT) revealed the presence of a large tumor on the pelvic floor, multiple metastases to the liver, bone 
A

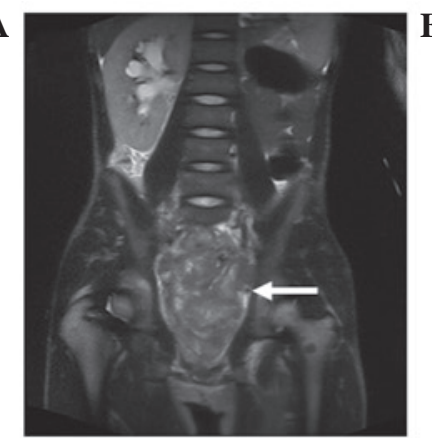

E

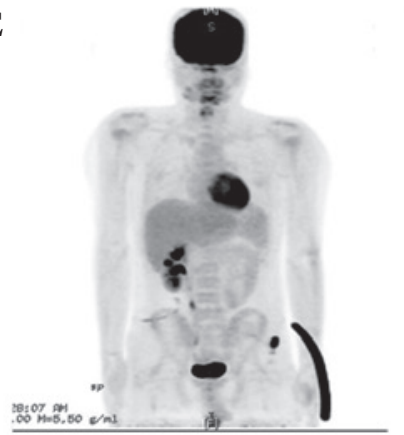

B

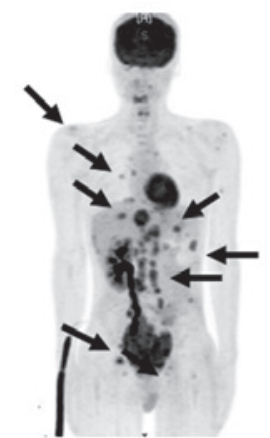

F

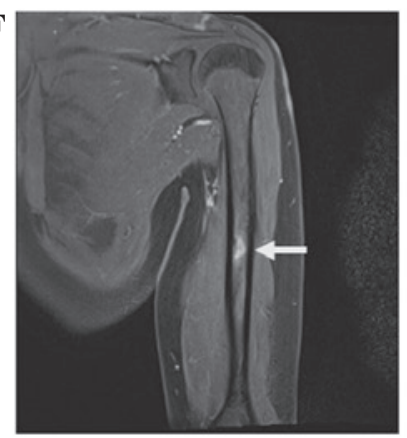

C

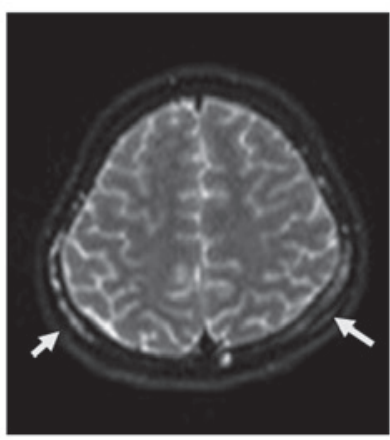

G

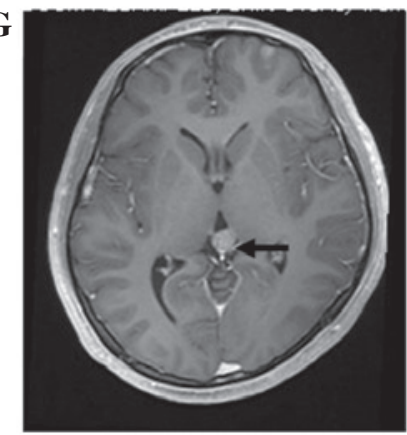

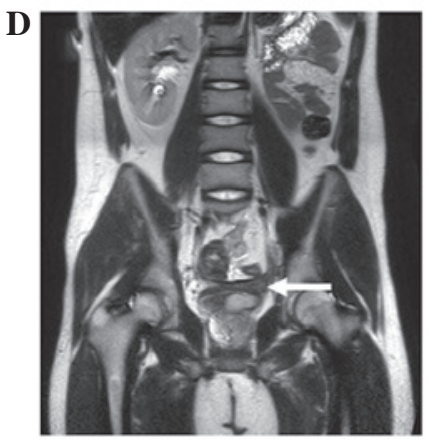

$\mathbf{H}$

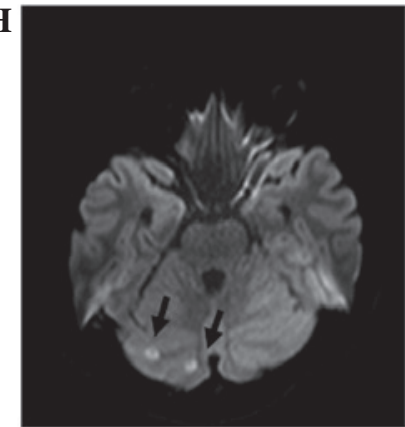

Figure 1. Radiographic findings (A-C) at diagnosis, (D and E) after eight courses of preoperative chemotherapy and (F-H) at recurrence. Radiographic findings include (A, C, D and F-H) magnetic resonance imaging (MRI) and (B and E) ${ }^{18}$ F-fluorodeoxyglucose positron emission tomography-computed tomography $\left({ }^{18} \mathrm{~F}\right.$-FDG PET-CT). In (A) and (D), arrows indicate the primary tumor on the pelvic floor. In (B), arrows indicate multiple metastases to bone, liver and lymph nodes at diagnosis. (C) Head MRI demonstrating multiple metastatic lesions in the internal table of calvaria (arrows) on diffusion-weighted imaging (DWI). (D) Abdominal T1-weighted MRI and (E) ${ }^{18}$ F-FDG PET-CT demonstrating notable shrinkage of the primary tumor on the pelvic floor and the disappearance of multiple metastatic lesions. (F-H) Radiographic findings indicating recurrence in bone and the central nervous system 1 year and 2 months after the initial diagnosis. (F) Gadolinium-enhanced T1-weighted MRI of the upper extremities demonstrating bone metastases in the left humerus (arrow). Head MRI demonstrating $(\mathrm{G})$ a solitary mass in the pineal body on DWI and (H) multiple cerebellar lesions on gadolinium-enhanced T1-weighted imaging.

A
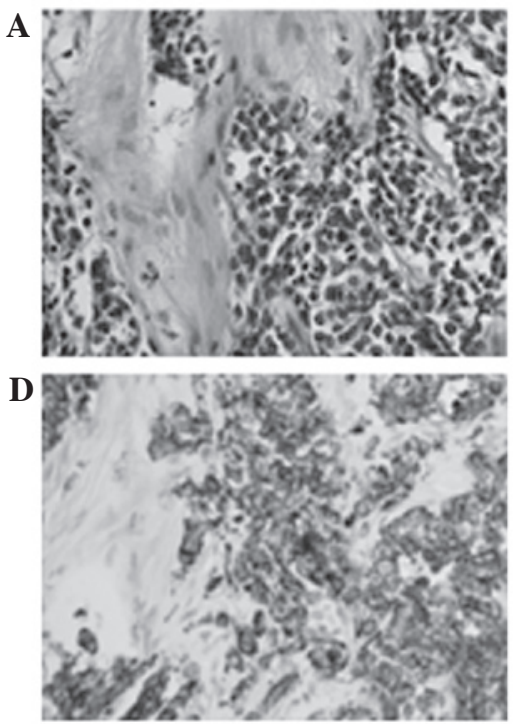
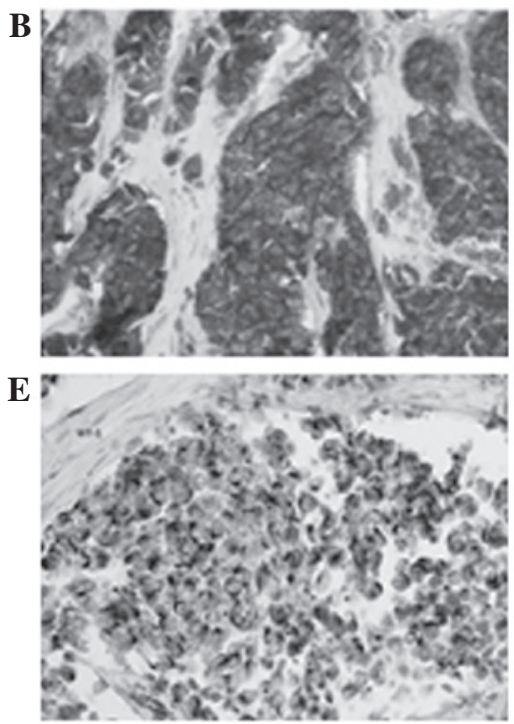
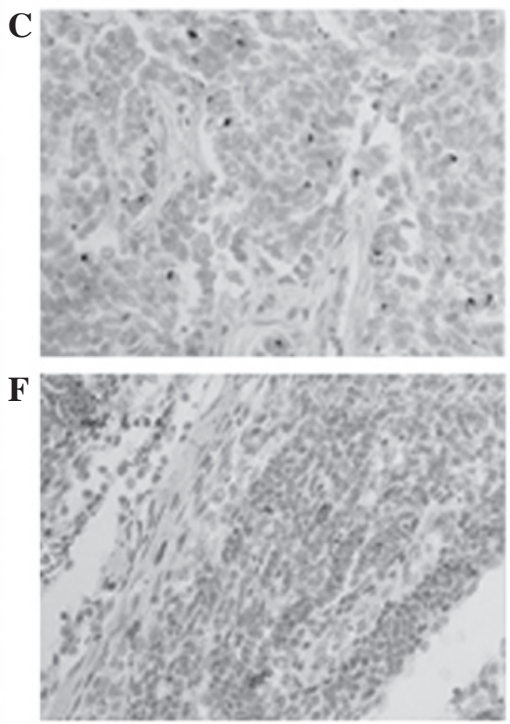

Figure 2. Immunohistochemical staining of the biopsy sample obtained from the left groin lymph node metastasis. (A) Histological observation revealed groups of small, undifferentiated cells embedded in a desmoplastic stroma. The sample was positive for (B) neuron-specific enolase, (C) desmin, (D) cytokeratin, (E) Wilm's tumor protein 1 and (F) cluster of differentiation 56 (stain, hematoxylin and eosin; magnification, x400).

and lymph nodes, and right kidney hydronephrosis due to compression of the ureter (Fig. 1A-C). Right renal agenesis, an ipsilateral seminal vesicle cyst and ejaculatory duct obstruction were also incidentally detected, all of which are typical findings of Zinner syndrome caused by the congenital loss of paramesonephric duct derivatives (5). However, to date, the association between DSRCT and Zinner syndrome has not been investigated.

In June 2012, the patient was transferred to Kyoto University Hospital (Kyoto, Japan), and underwent open biopsy of the left groin lymph node metastasis. Histological observation of a biopsy sample revealed groups of small, round, undif- 


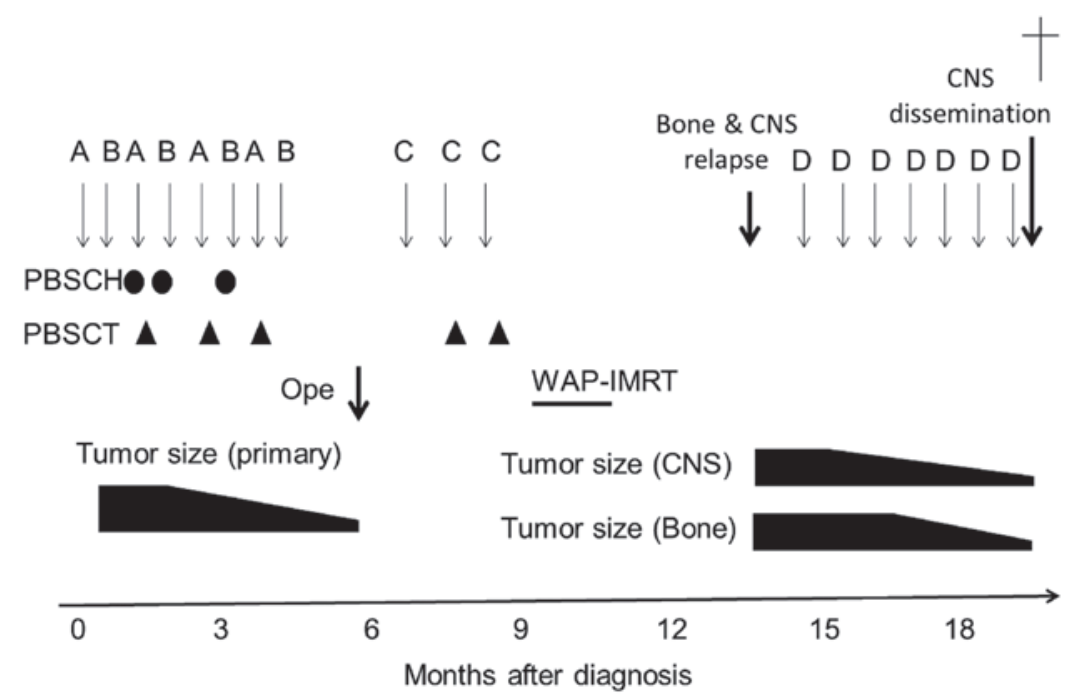

Figure 3. Clinical course of the patient. The patient received eight courses of chemotherapy, consisting of vincristine, doxorubicin or pirarubicin, and cyclophosphamide (Cy) (A), and ifosfamide and etoposide (B). Next, Ope was performed, followed by three courses of post-operative chemotherapy, consisting of topotecan and $\mathrm{Cy}(\mathrm{C})$, and WAP-IMRT. Following central nervous system and bone relapse, the patient received seven courses of chemotherapy consisting of irinotecan and temozolomide (D). Circles and triangles indicate PBSCH and PBSCT, respectively. CNS, central nervous system; PBSCH, peripheral blood stem cell harvests; PBSCT, peripheral blood stem cell transplantation; Ope, gross total resection of the primary and metastatic lesions; WAP-IMRT, whole abdominopelvic intensity-modulated radiation therapy.
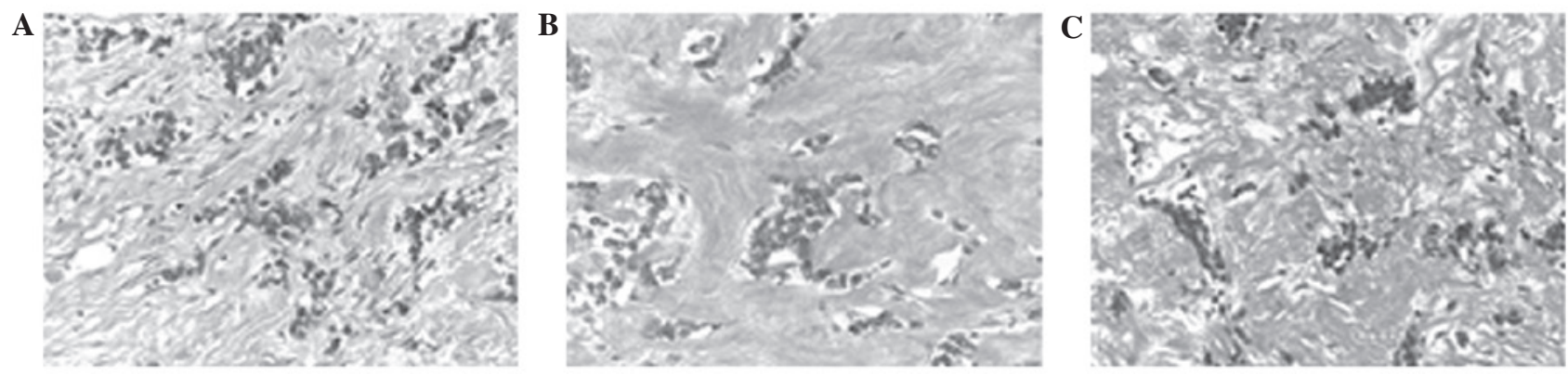

Figure 4. Histological examination of excised (A) primary and metastatic lesions identified on the (B) liver and (C) diaphragm (stain, hematoxylin and eosin; magnification, $\mathrm{x} 400)$.

ferentiated cells embedded in a desmoplastic stroma (Fig. 2A). Immunohistochemistry of the specimen was positive for neuron-specific enolase, desmin, cytokeratin and WT1, focally positive for CD56, and negative for CD99, myogenic differentiation 1 and S100 (Fig. 2B-F). The patient was diagnosed with DSRCT based on detection of the EWS/WT1 fusion transcript by reverse transcription (RT)-polymerase chain reaction (PCR). Briefly, RT-PCR was performed using the PE7000 PCR detection system (Perkin-Elmer, Inc., Waltham, MA, USA). The reaction system contained $1 \mu \mathrm{l}$ cDNA, $2 \mu \mathrm{l}$ forward and reverse primers, $5 \mu \mathrm{l}$ PCR buffer, $3 \mu \mathrm{l} \mathrm{MgCl}_{2}, 0.2 \mu \mathrm{l}$ rTaq enzyme, $5 \mu \mathrm{l}$ dNTPs $(2 \mathrm{mM})$ and $31.8 \mu \mathrm{l} \mathrm{dH}_{2} \mathrm{O}$. PCR was performed under the following conditions: Initial denaturation step at $94^{\circ} \mathrm{C}$ for $2 \mathrm{~min}$, followed by $35 \mathrm{cycles}$ of $94^{\circ} \mathrm{C}$ for $30 \mathrm{sec}, 62^{\circ} \mathrm{C}$ for $30 \mathrm{sec}$ and $72^{\circ} \mathrm{C}$ for $1 \mathrm{~min}$, with a final extension step at $72^{\circ} \mathrm{C}$ for $6 \mathrm{~min}$. No metastatic disease was detected by bone marrow aspiration or MRI of the head.

The patient's clinical course is indicated in Fig. 3. In June 2012, following percutaneous nephrostomy and colostomy, the patient was initially treated with eight courses (18-21 day cycles) of multi-agent chemotherapy. A modified protocol of the P6 regimen (2) was used, as follows: Vincristine $\left(2 \mathrm{mg} / \mathrm{m}^{2}\right.$, day 1), doxorubicin (DOX; $37.5 \mathrm{mg} / \mathrm{m}^{2}$, days 1 and 2; using pirarubicin instead of DOX for the fifth and sevenths courses) and cyclophosphamide [Cy; $1.2 \mathrm{~g} / \mathrm{m}^{2}$ (day 1) for the first course and $2.1 \mathrm{~g} / \mathrm{m}^{2}$ (days 1 and 2) for the third, fifth and seventh courses], alternating with ifosfamide (IFO; $1.8 \mathrm{~g} / \mathrm{m}^{2}$, days $1-5$ ) and etoposide (VP16; $100 \mathrm{mg} / \mathrm{m}^{2}$, days $1-5$ ). Peripheral blood stem cells (PBSCs), containing a total of 7.4, 4.5 and $5.0 \times 10^{6}$ cells $/ \mathrm{kg} \mathrm{CD} 34^{+}$cells, were harvested following mobilization with granulocyte-stimulating factor after the second, fourth and fifth courses of chemotherapy, respectively. To hasten the hematological recovery, PBSCs, containing a total of 1.2, 1.0 and $1.1 \times 10^{6}$ cells $/ \mathrm{kg} \mathrm{CD} 34^{+}$cells, were infused after the third, fifth and seventh courses of chemotherapy, respectively. Following the completion of eight courses of chemotherapy over 25 weeks, the primary tumor markedly regressed and all metastatic lesions except one at the caudate lobe of the liver disappeared (Fig. 1D and E). In November 2012, the patient underwent a gross total resection of the primary tumor on the pelvic floor, a subtotal resection of the caudate lobe of the liver, while sparing the rectum, bladder and ureter. Intraoperatively, 
Table I. Summary of cases of desmoplastic small round cell tumors with CNS involvement.

\begin{tabular}{|c|c|c|c|c|c|c|}
\hline $\begin{array}{l}\text { Age, years/ } \\
\text { gender }\end{array}$ & $\begin{array}{l}\text { Disease } \\
\text { status }\end{array}$ & $\begin{array}{l}\text { CNS } \\
\text { lesions }\end{array}$ & Surgery & Treatment & Outcome & Reference \\
\hline $24 / \mathrm{M}$ & Primary & $\begin{array}{l}\text { Posterior } \\
\text { fossa }\end{array}$ & $\begin{array}{c}\text { Partial } \\
\text { resection }\end{array}$ & $\begin{array}{l}\text { PCNU, CDDP, VP16, } \\
\text { local irradiation, it-MTX }\end{array}$ & AWD (unknown) & 5 \\
\hline $37 / \mathrm{M}$ & Primary & $\mathrm{CPA}$ & $\begin{array}{l}\text { Partial } \\
\text { resection }\end{array}$ & $\begin{array}{l}\text { CBDCA, TMZ, } \\
\text { radiation }[\mathrm{WB} \text { and local } \\
(\mathrm{CPA}, \text { spine })]\end{array}$ & DOD (24 months) & 6 \\
\hline 39/M & Primary & CPA, spine & $\begin{array}{l}\text { Partial } \\
\text { resection }\end{array}$ & $\begin{array}{l}\text { CDDP, VP16, IFO, } \\
\text { radiation [WB and local } \\
(\mathrm{CPA}, \text { spine })]\end{array}$ & AWD (27 months) & 6 \\
\hline $16 / \mathrm{M}$ & Relapsed & $\begin{array}{l}\text { Pineal body, } \\
\text { cerebellum }\end{array}$ & No & CPT11, TMZ & DOD (21 months) & $\begin{array}{l}\text { Current } \\
\text { case }\end{array}$ \\
\hline
\end{tabular}

CNS, central nervous system; M, male; PCNU, nitrosourea; CDDP, cisplatin; VP16, etoposide; AWD, alive with disease; it-MTX, intrathecal methotrexate; CPA, cerebellopontine angle; CBDCA, carboplatin; TMZ, temozolomide; DOD, died of disease; WB, whole brain; IFO, ifosphamide; CPT11, irinotecan.

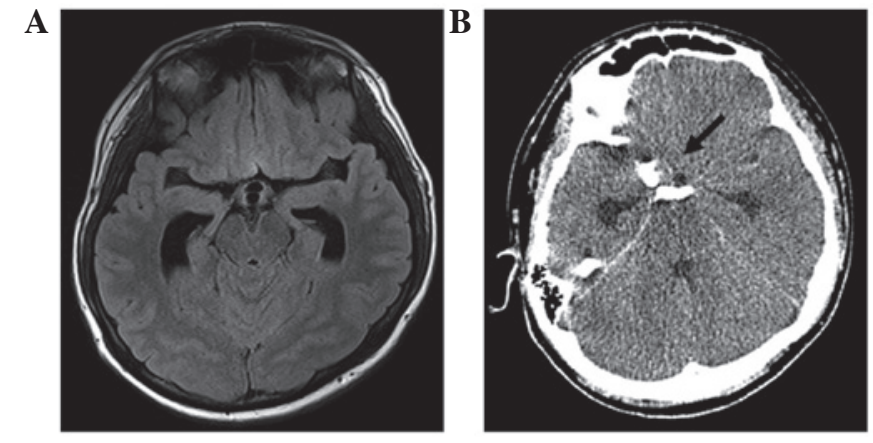

Figure 5. Radiographic findings following seven courses of chemotherapy with irinotecan and temozolomide. (A) A head magnetic resonance image demonstrating dilatation of the lateral ventricles on fluid-attenuated inversion recovery T2-weighted imaging. (B) Head computed tomography demonstrated subarachnoid hemorrhage (arrow) at the base of the brain two days later.

multiple disseminated tumors were identified on the peritoneum and diaphragm, which had not been identified by preoperative imaging. Subsequently, radical resection of the disseminated tumors on the peritoneum and diaphragm was also performed. Histological examination of the excised primary and metastatic lesions revealed scattered viable cells embedded in a dense desmoplastic stroma (Fig. 4A-C). Subsequently, in January 2013, the patient received one 28-day course of post-operative chemotherapy using topotecan (Topo; $0.75 \mathrm{mg} / \mathrm{m}^{2}$, days $1-5$ ) and Cy $\left(250 \mathrm{mg} / \mathrm{m}^{2}\right.$, days $\left.1-5\right)$, a combination that is considered to have potent antitumor activity against DRSCT (6). Thereafter, the patient was treated with two 28-day cycles of high-dose chemotherapy using Topo $\left(3 \mathrm{mg} / \mathrm{m}^{2}\right.$, days $\left.1-5\right)$ and Cy $\left(1 \mathrm{mg} / \mathrm{m}^{2}\right.$, days 3-5), followed by the infusion of 57 and $48 \mathrm{ml}$ PBSCs, containing 1.8 and $1.6 \times 10^{6} \mathrm{CD} 34^{+}$cells $/ \mathrm{kg}$, respectively.

There were no severe regimen-related toxicities and no serious infections during the pre- or post-operative chemotherapy treatment periods. Finally, in March 2013, the patient received whole abdominopelvic intensity-modulated radiation therapy at a dose of 30 Gy in 20 fractions for 28 days. The patient was discharged without any active lesions 11 months after the initial diagnosis.

Three months after discharge, the patient was asymptomatic, however, MRI of the upper extremities demonstrated bone metastases in the left humerus on follow-up (Fig. 1F). Furthermore, MRI of the head demonstrated a mass in the pineal body and multiple cerebellar lesions (Fig. $1 \mathrm{G}$ and $\mathrm{H}$ ). No evidence of active disease was revealed by abdominal and spinal MRI or by cerebrospinal fluid (CSF) examination. The patient was treated with irinotecan (CPT11; $35 \mathrm{mg} / \mathrm{m}^{2}$, days $\left.1-5\right)$ and temozolomide (TMZ; $120 \mathrm{mg} / \mathrm{m}^{2}$, days $1-5$ ), without irradiation, with the expectation that synergistic antitumor activity would be exhibited and that TMZ could cross the blood-brain barrier. Subsequent to four 28-day cycles of chemotherapy, a partial response of the bone metastasis and pineal body was observed, whereas the response of the cerebellar lesions was stable disease.

In March 2014, the patient was readmitted to Kyoto University Hospital due to a severe headache, which had lasted for one week following seven 28-day cycles of chemotherapy. Fluid-attenuated inversion recovery MRI of the head demonstrated dilatation of the lateral ventricles, although the intracranial lesions had not increased in size (Fig. 5A). The CSF cell count was 20 cells $/ \mu 1$ and CSF cytology was positive for malignant, small, round cells, indicating CNS dissemination of DSRCT. The CSF protein level was $34.9 \mathrm{mg} / \mathrm{dl}$ (normal range, 10.0-40.0 mg/dl) and glucose was $22 \mathrm{mg} / \mathrm{dl}$ (normal range, 40-75 mg/dl; serum glucose, $116 \mathrm{mg} / \mathrm{dl}$, normal range, $78-110 \mathrm{mg} / \mathrm{dl}$ ). Two days later, the patient suddenly exhibited a decreased level of consciousness and a head CT revealed a subarachnoid hemorrhage at the base of the brain (Fig. 5B). As a consequence, the patient succumbed due to progressive CNS disease 1 year and 9 months after the initial diagnosis. An autopsy was not performed, as permission could not be obtained from the family.

\section{Discussion}

Gross tumor resection is strongly associated with prolonging the overall survival of patients with DSRCT (4). Intensive 
chemotherapy, such as the P6 protocol, is initially effective for the majority cases of DSRCT (2). However, severe bone marrow suppression, even when granulocyte-stimulating factor is used, requires the intervals between treatments to be lengthened after a number of cycles. In a previous study, it was identified that the regrowth of chemotherapy-resistant tumors eventually hindered gross tumor resection, and that almost all patients undergoing incomplete resection succumbed to the disease within 2 years (4).

The following chemotherapy regimen was planned for the current patient in response to a large intra-abdominal DSRCT: Increasing dose-intensity by decreasing the interval between chemotherapy cycles, while maintaining an identical total dose throughout. As a result, sustained antitumor activity was observed following eight cycles of pre-operative chemotherapy using frequent PBSC support at $\sim 3$-week intervals, and gross total resection of the primary and intra-abdominal metastatic tumors was completed. Furthermore, no active disease was observed at the site of the abdominal or pelvic lesions at least 1 year and 9 months after the initial diagnosis. Thus, interval-compressed chemotherapy, in combination with surgery and local irradiation, is a promising treatment strategy, at least for the control of localized DSRCT.

There have been three reported cases of a primary CNS tumor in DRSCT to date $(7,8)$, but this is the first report of DSRCT recurrence in the CNS (Table I). Although rare, reports of neuroblastoma or EWS recurrence in the CNS are on the increase, which may be associated with improvements in the outcome due to aggressive multimodal therapy $(9,10)$. Notably, the present case exhibited multiple metastatic lesions in the internal table of calvaria at the initial diagnosis, which raises the possibility that the CNS involvement of DSRCT was associated with tumor extension through the dura or skull into the adjacent superficial brain parenchyma, as previously reported in neuroblastoma and EWS $(9,10)$. Thus, further successful advances in treatments for DSRCT will require awareness of the potential for CNS recurrence and the identification of risk factors for such an unusual pattern of metastasis.

The three previously reported cases of a primary CNS tumor in DSRCT followed aggressive courses, similar to that of intra-abdominal DSRCT, despite an initial response to chemotherapy regimes, such as IFO, VP16, TMZ and carboplatin, in combination with whole-brain or spinal irradiation (Table I) $(7,8)$. In the current case, the combination of CPT11 and TMZ was selected as salvage therapy for CNS recurrence of DSRCT, which has exerted an good antitumor effect for refractory or relapsed neuroblastoma and EWS $(11,12)$.
Indeed, the combination of CPT11 and TMZ was initially effective against the CNS metastatic lesions; however, the patient ultimately succumbed due to progressive CNS disease. Therefore, additional studies are required to establish a novel chemotherapy, in combination with craniospinal irradiation, to prevent or treat DSRCT of the CNS.

\section{References}

1. Jordan AH and Pappo A: Management of desmoplastic small round-cell tumors in children and young adults. J Pediatr Hematol Oncol 34 (Suppl 2): S73-S75, 2012.

2. Gerald WL, Ladanyi M, de Alava E, Cuatrecasas M, Kushner BH, LaQuaglia MP and Rosai J: Clinical, pathologic, and molecular spectrum of tumors associated with $\mathrm{t}(11 ; 22)$ (p13;q12): Desmoplastic small round-cell tumor and its variants. J Clin Oncol 16: 3028-3036, 1998.

3. Kushner BH, LaQuaglia MP, Wollner N, Meyers PA,Lindsley KL, Ghavimi F, Merchant TE, Boulad F, Cheung NK, Bonilla MA, et al: Desmoplastic small round-cell tumor: Prolonged progression-free survival with aggressive multimodality therapy. J Clin Oncol 14: 1526-1531, 1996.

4. Lal DR, Su WT, Wolden SL, Loh KC, Modak S and LaQuaglia MP: Results of multimodal treatment for desmoplastic small round cell tumors. J Pediatr Surg 40: 251-255, 2005.

5. Livingston $L$ and Larson CR: Seminal vesicle cysts with ipsilateral renal agenesis. AJR Am J Roentgenol 175: 177-180, 2000.

6. Sayors RL III, Stine KC, Sullivan J, Kepner JL, Wall DA, Bernstein ML, Harris MB, Hayashi R and Vietti TJ; Pediatric Oncology Group: Cyclophosphamide plus topotecan in children with recurrent or refractory solid tumors: A pediatric oncology group phase II study. J Clin Oncol 19: 3463-3469, 2001.

7. Tison V, Cerasoli S, Morigi F, Ladanyi M, Gerald WL and Rosai J: Intracranial desmoplastic small-cell tumor. Report of a case. Am J Surg Pathol 20: 112-117, 1996.

8. Neder L, Scheithauer BW, Turel KE, Arnesen MA, Ketterling RP, Jin L, Moynihan TJ, Giannini C and Meyer FB: Desmoplastic small round cell tumor of the central nervous system: Report of two cases and review of the literature. Virchows Arch 454: 431-439, 2009.

9. Matthay KK, Brisse H, Couanet D, Couturier J, Bénard J, Mosseri V, Edeline V, Lumbroso J, Valteau-Couanet D and Michon J: Central nervous system metastasis in neuroblastoma: Radiologic, clinical and biologic features in 23 patients. Cancer 98: 155-165, 2003.

10. Kuo MF, Lin SM and Tu YK: Solitary cerebellar metastasis from Ewing's sarcoma: Case report and review of the literature. Childs Nerv Syst 9: 428-430, 1993.

11. Bagatell R, London WB, Wagner LM, Voss SD, Stewart CF, Maris JM, Kretschmar C and Chon SL: Phase II study of irinotecan and temozolomide in children with relapsed or refractory neuroblastoma: A children's oncology group study. J Clin Oncol 29: 208-213, 2011.

12. Wagner LM, McAllister N, Goldsby RE, Rausen AR, McNall-Knapp RY, McCaeville MB and Albritton K: Temozolomide and intravenous irinotecan for treatment of advanced Ewing sarcoma. Pediatr Blood Cancer 48: 132-139, 2007. 